\title{
Human amygdala volume is predicted by common DNA variation in the stathmin and serotonin transporter genes
}

\author{
D Stjepanović ${ }^{1}$, V Lorenzetti ${ }^{2,3}$, M Yücel $^{2,3}$, Z Hawi ${ }^{1,3}$ and MA Bellgrove ${ }^{1,3}$
}

Despite the relevance of changes in amygdala volume to psychiatric illnesses and its heritability in both health and disease, the influence of common genetic variation on amygdala morphology remains largely unexplored. In the present study, we investigated the influence of a number of novel genetic variants on amygdala volume in 139 neurologically healthy individuals of European descent. Amygdala volume was significantly associated with allelic variation in the stathmin (STMN1) and serotonin transporter (SLC6A4) genes, which have been linked to healthy and disordered affective processing. These results were replicated across both manual and automated methods of amygdala parcellation, although manual tracing showed stronger effects, providing a cautionary note to studies relying on automated parcellation methods. Future studies will need to determine whether amygdala volume mediates the impact of stathmin and serotonin transporter gene variants on normal and dysfunctional emotion processing.

Translational Psychiatry (2013) 3, e283; doi:10.1038/tp.2013.41; published online 16 July 2013

\section{Introduction}

The amygdala is central to many aspects of emotional and cognitive processing ${ }^{1}$ and is arguably the brain region most consistently implicated in neurodevelopmental and neuropsychiatric disorders. ${ }^{2}$ Human research has consistently demonstrated the importance of the amygdala to emotion processing ${ }^{3}$ and cognition (for example, in memory formation ${ }^{4,5}$ ). There is consistent evidence that damage to the amygdala results in disruption to emotional cognitive processing in humans, including the recognition and experience of emotions such as fear. ${ }^{6-8}$

Converging lines of evidence suggest that the amygdala is structurally and functionally altered in psychiatric disorders. Individuals with spider ${ }^{9}$ and social ${ }^{10}$ phobia show increased amygdala responding to presentations of feared stimuli, whereas individuals with depression show reduced amygdala responding in response to sad stimuli. ${ }^{11}$ Amygdala activation to emotional faces has also been shown to predict symptom reduction in major depressive disorder. ${ }^{12}$ Further to this, alterations in amygdala volume have been associated with a number of disorders, including unmedicated depression, ${ }^{13}$ obsessive-compulsive disorder ${ }^{14}$ and autism, where amygdala volume is significantly reduced in both individuals with autism and their unaffected siblings. ${ }^{15}$

Although large-scale twin studies have shown that amygdala volume is highly heritable, ${ }^{16,17}$ its molecular genetic architecture remains to be determined. Here, we examined the influence of common DNA variation in a sample of neurologically healthy adults, emphasizing genes that are highly expressed in the human amygdala, focusing on those encoding the serotonin transporter, oxytocin receptor and stathmin protein. Within the gene encoding the serotonin transporter (SLC6A4), we investigated three variants: the insertion/deletion polymorphism within the serotonin transporter gene-linked promoter region (5-HTTLPR), a singlenucleotide polymorphism (SNP) within 5-HTTLPR (rs22531) and a variable number tandem repeat within the second intron of this gene (STin2). Within the oxytocin receptor (OXTR) and stathmin 1 (STMN1) genes, we focused our search on two previously studied SNPs (rs53576 and rs182455, respectively).

The 5-HTTLPR consists of a long (I) and a short (s) allele, with the $s$ allele showing a 43-bp reduction (initially described as a 44-bp reduction) ${ }^{18,19}$ in length to that of the I allele, and reduced mRNA transcription levels, ${ }^{20}$ which may in turn lead to reduced efficiency of the serotonin transporter. The presence of at least one $s$ allele has been repeatedly associated with increased amygdala function at rest ${ }^{21}$ and in response to emotional stimuli. ${ }^{22}$ This association between amygdala hyperactivity in s allele carriers has been confirmed by two meta-analyses. ${ }^{23,24}$ In addition, Scherk et al. ${ }^{25}$ found that right amygdala volume was significantly larger in those carrying at least one s allele. We also examined rs25531, a SNP that is thought to alter the function of the 5-HTTLPR variants. ${ }^{26}$ The presence of a $\mathrm{G}$ (but not an A) nucleotide is thought to alter and reduce the transcriptional efficacy of the I allele to function more similarly to that of an $s$ allele, ${ }^{18,26,27}$ although inconsistencies have been reported. ${ }^{28,29}$ As s allele carriers show altered amygdala morphometry, the presence of a $\mathrm{G}$ nucleotide within rs25531 may also be associated with changes in amygdala volume.

${ }^{1}$ Queensland Brain Institute, The University of Queensland, Brisbane, Queensland, Australia; ${ }^{2}$ Melbourne Neuropsychiatry Centre, Department of Psychiatry, University of Melbourne and Melbourne Health, Melbourne, Victoria, Australia and ${ }^{3}$ School of Psychology and Psychiatry, Monash University, Melbourne, Victoria, Australia Correspondence: D Stjepanović, Queensland Brain Institute, The University of Queensland, Brisbane, Queensland 4072, Australia.

E-mail: d.stjepanovic@uq.edu.au

Keywords: amygdala; genetics; morphology; oxytocin; stathmin; serotonin

Received 19 April 2013; accepted 22 April 2013 
STin2, a 16-17 bp variable number tandem repeat polymorphism, presents with two major alleles corresponding to 10- and 12-repeat units, and has been found to be in linkage disequilibrium with the 5-HTTLPR polymorphism in different populations. ${ }^{30-32}$ The 12-repeat allele has been reported to be a transcriptional enhancer, ${ }^{33}$ showing reduced luciferase expression in embryonic and murine stem cells. ${ }^{34,35}$ Paradoxically, Bah et al. $^{36}$ found that 12-repeat homozygotes displayed lower serotonin transporter availability in the brain, despite the aforementioned evidence of increased transcription. DNA variation in STin2 has been associated with a number of affective disorders, ${ }^{37,38}$ and recent evidence suggests a combinatorial interaction between 5-HTTLPR and STin2. ${ }^{39,40}$ Given these associations, it remains to be tested if STin2 variation is associated with amygdala volume.

The oxytocin peptide has been shown to be important in regulating social behavior, with oxytocin demonstrated to have a role in the effects of social stress, emotion recognition and social memory. ${ }^{41}$ Because of this, and the high density of oxytocin receptors within the amygdala, ${ }^{42}$ we investigated the relationship between DNA variation in the oxytocin receptor gene and amygdala volume. We focused on a SNP (rs53576) within the oxytocin receptor gene, which has been associated with prosocial temperament and the response of the amygdala during facial emotion processing, as well as a reported effect on amygdala volume in male participants. ${ }^{43}$

The search for the genetic basis of brain function has predominantly focused on genetic variants implicated in neural transmission. An alternative approach is the targeting of genes that regulate neural plasticity. Stathmin, a regulator of microtubule formation, is highly expressed in the amygdala ${ }^{44-46}$ and is crucial for fear processing in mice. ${ }^{46}$ Shumyatsky et al. $^{46}$ found that stathmin knock-out mice exhibited deficient long-term potentiation in the amygdala, and an inability to recognize danger in innately aversive environments. Interestingly, these mice displayed similar deficiencies in threat assessment to mice that had their basolateral amygdala lesioned. ${ }^{45}$ Expanding this work to humans, Brocke et al. ${ }^{47}$ investigated two purportedly functional SNPs within the control region of the gene encoding for stathmin. They reported an influence of a SNP within stathmin (rs182455) on amygdala-mediated responding during an emotionally modulated acoustic startle paradigm. Given the strong role of stathmin in amygdala structure and function in animals, it is possible that the effect of rs 182455 on emotion processing in humans is mediated by amygdala morphometry.

The aim of the present study was to investigate the influence of the above common genetic variants on amygdala volume, as determined using manual and automated (Freesurfer) parcellation protocols. The use of automated software packages to quantify amygdala volume is increasing with the availability of large databases of high-resolution magnetic resonance images (MRIs), and because of collaborative efforts such as the ENIGMA consortium (http://enigma.loni. ucla.edu/). Although direct comparisons between manual tracing and automated segmentation protocols show high overlap and significant positive correlation, ${ }^{48}$ it is unclear whether manual and automated methods are equally sensitive to the small effect sizes of genetic influences on amygdala volume.

We hypothesized that amygdala volume would be increased in s allele carriers of the 5-HTTLPR polymorphism based upon previous findings of increased risk for mental illness and increased amygdala function and volume in s allele carriers. We predicted that amygdala volume would vary as a function of allelic variation in rs53576 of the oxytocin receptor gene. As the 10-repeat allele of STin2 has been linked to a number of mental illnesses, we predicted the presence of the 10-repeat allele would be associated with reduced amygdala volume. Similarly, we predicted that the presence of a $\mathrm{C}$ allele of stathmin rs182455, which has been related to a reduction in cognitive-affective processing, ${ }^{49}$ would be associated with reduced amygdala volume.

\section{Materials and methods}

Participants. One hundred and thirty-nine right-handed participants (seventy-two male, mean age 22 years, range 18-40 years) were recruited from the University of Queensland. All participants were of European ancestry to avoid any possible population stratification artifacts. Participants were all right-handed and were screened for any lifetime history of head trauma, neurological or psychiatric disorders, and active or recent use of psychoactive medications or drugs. Thirteen participants failed genotyping for at least one gene and were removed from subsequent analyses. Written informed consent was obtained from all participants before study participation. The study was approved by the Medical Research Ethics Committee of the University of Queensland.

MRI acquisition and volume measurement protocols. High-resolution T1-weighted structural MPRAGE images were collected at a voxel resolution of $0.9 \mathrm{~mm}$ isotropic on a 1.5-T Siemens (Siemens Medical Solutions, Erlangen, Germany) Sonata $(N=82)$ and a 3-T Siemens TRIO $(N=57)$. Image preprocessing was conducted using the FMRIB Software Library. ${ }^{50}$ Images were stripped of extra-cerebral tissues using the Brain Extraction Tool, ${ }^{51}$ and then reoriented in space to align with the MNI ICBM152 template using FMRIB's Linear Image Registration Tool. ${ }^{52}$ The resulting realignment matrix was then applied to the original MPRAGE images, which were then imported into the ANALYZE 10 software package (Mayo Clinic, Rochester, MN, USA) for manual tracing.

Amygdalae were manually traced by the same investigator (DS) who was blind to genotype, based on a previously validated protocol, ${ }^{53}$ with slight modifications defining the boundary between the amygdala and the hippocampus. ${ }^{54}$ Intra-class correlation coefficients (absolute agreement) for right and left amygdalae were 0.94 and 0.94 , respectively, for intra-rater reliability; and 0.97 and 0.91 for inter-rater reliability against an experienced amygdala tracer (VL) and based on 10 randomly selected images.

Manual tracing of the amygdala boundaries was performed on coronally displayed MRI slices and proceeded in a caudal to rostral direction. Amygdala boundaries were defined based upon neighboring gray- and white-matter structures such as 
the hippocampus. Appearing initially as gray matter above the temporal horn, the amygdala was bounded by a thin strip of white matter at its superior-lateral edge, separating it from the claustrum and the tail of the caudate; the angular bundle and entorhinal cortex bounded the amygdala medially; the semilunar gyrus defined the superior-medial boundary; and the hippocampus and the temporal white matter defined the inferior and inferior-lateral boundaries, respectively. The anterior boundary of the amygdala, which can be difficult to observe in MRI images, was defined as either the slice posterior to the appearance of the optic chiasm, or where the lateral sulcus closes to form the entorhinal sulcus, whichever was more posterior. Volumetric estimates were obtained by summing all voxels within the left and right amygdalae within all traced slices.

To contrast against the results from the manual tracing protocol, we also computed amygdala volumes with the fully automated subcortical segmentation component of Freesurfer's (http://surfer.nmr.mgh.harvard.edu/) cortical reconstruction process, which has been shown to be more highly correlated with hand tracing than other automated protocols. ${ }^{48}$ This also provided a measure of intracranial volume, which was used as a covariate in all analyses, because of the influence of intracranial volume on amygdala volumetric measurements. ${ }^{55}$

Genotyping. DNA was isolated from $2 \mathrm{ml}$ saliva collected using Oragene self-collection kits (DNA Genotek, Kanata, Ontario, Canada). Primers for PCR amplification were designed using Primer $3,{ }^{56}$ and are contained in Table 1. DNA was amplified using standardized procedures: PCR for rs22531 and STin2, and touchdown PCR for 5-HTTLPR and rs53576. PCR product was digested using BamHI and Mspll enzymes (New England Biolabs, Ipswich, MA, USA) to cut the rs53576 and rs22531 PCR products, respectively. Following electrophoresis in 3\% agarose gel, the PCR and digestion products were visualized using $5 \mu$ l of SYBR safe gel stain (Invitrogen, Carlsbad, CA, USA) or ethidium bromide where SYBR safe stain failed to visualize bands. We utilized an automated DNA fragment QIAxcel system (QIAGEN, Hilden, Germany) to confirm gel electrophoresis. The rs182455 SNP was genotyped using an Applied Biosystems (Foster City, CA, USA) Taqman ${ }^{\mathbb{B}}$ assay running on a Lightcycler
480 (Roche, Rotkreuz, Switzerland), following manufacturer's instructions.

An additive model was used to categorize genotypes for all analyses involving the 5-HTTLPR polymorphism, rs182455 and rs53576. As the $s$ allele of the 5-HTTLPR polymorphism has been associated with risk for mental illness and altered amygdala activation, genotype was coded to reflect these associations such that II, Is and ss were coded as 0,1 and 2, respectively. Cases where an I allele for 5-HTTLPR co-occurred with a G SNP for rs25531 were recoded as s alleles. For STin2, we employed a 10-repeat dominant model as used by Sarosi et al., ${ }^{57}$ coding 10/10 and 10/12 genotypes as 1 and 12/12 as 2. Rare genotypes, 9/9 and 9/10, were excluded from analysis as they represented less than one percent of all cases. We used an additive model to classify rs182455, coding for the major allele, such that TT, CT and CC were coded as 0,1 and 2, respectively. For rs53576, we combined the less common $A / A$ and $A / G$ genotypes for our comparison against $\mathrm{G} / \mathrm{G}$, as has been done previously by others. $^{58,59}$

\section{Results}

A detailed description of brain volumetric measurements is provided in Table 2 . The mean values for the manual tracing data are consistent with amygdala volumes measured in postmortem brains. ${ }^{60-63}$ Average automated values are in line with previous reports, which also note larger volume values resulting from automated parcellation methods. ${ }^{48}$ Amygdala volumes obtained from manual and automated parcellation were significantly correlated, $r(137)=0.543, P<0.001$, as shown in Figure 1. Figure 2 presents a Bland-Altman plot ${ }^{64,65}$ illustrating the agreement between manual and automated parcellation volumes.

The relationship between genotype and amygdala volume was measured by performing linear regressions, separately for the type of parcellation method (that is, manual and automated), with results detailed in Table 3 . KolmogorovSmirnoff tests were used to assess the assumption of central tendency and confirmed that all dependent measures were significantly normal, all $\mathrm{D}(136)<0.08, P>0.10$. Regression analyses were run in two steps: first, we controlled for the impact of major confounders on amygdala volumes, including

Table 1 Genotyping methods and frequencies

\begin{tabular}{|c|c|c|c|c|c|c|}
\hline Gene & Variant & Alleles & Digest & Product/digest length & Primers $\left(5^{\prime} \rightarrow 3^{\prime}\right)$ & Genotype frequencies $(\mathrm{N})$ \\
\hline \multirow[t]{3}{*}{ SLC6A4 } & 5-HTTLPR & $\begin{array}{l}\text { Short (s) } \\
\text { Long (I) }\end{array}$ & - & $\begin{array}{l}486 \mathrm{bp} \\
529 \mathrm{bp}\end{array}$ & $\begin{array}{l}\text { F: GGC GTT GCC GCT CTG AAT GC } \\
\text { R: GAG GGA CTG AGC TGG ACA ACC AC }\end{array}$ & $\begin{array}{l}\text { SS (35) } \\
\text { SL (54) } \\
\text { LL (43) }\end{array}$ \\
\hline & rs25531 & $\begin{array}{l}A \\
G\end{array}$ & Mspl & $\begin{array}{c}174+168+125+62 b p \\
342+125+62 b p\end{array}$ & 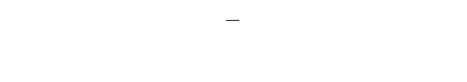 & $\begin{array}{l}A A(111) \\
A G(14) \\
G G(1)\end{array}$ \\
\hline & STin2 & $\begin{array}{l}10 \text { Repeat } \\
12 \text { Repeat }\end{array}$ & - & $\begin{array}{l}279 \mathrm{bp} \\
312 \mathrm{bp}\end{array}$ & $\begin{array}{l}\text { F: CAG AAT GGA GGG GGT CAG TA } \\
\text { R: TGT TCC TAG TCT TAC GCC AGT G }\end{array}$ & $\begin{array}{l}10 / 10(26) \\
10 / 12(60) \\
12 / 12(43)\end{array}$ \\
\hline OXTR & rs53576 & $\begin{array}{l}\mathrm{C} \\
\mathrm{T}\end{array}$ & BamHI & $\begin{array}{c}238 b p \\
168+70 b p\end{array}$ & $\begin{array}{l}\text { F: GCC TGG TTT GAA CTG TTT CC } \\
\text { R: ATT CAC TCT GGG CCA TGA AG }\end{array}$ & $\begin{array}{l}\text { CC (78) } \\
\text { CT (46) } \\
\text { TT (5) }\end{array}$ \\
\hline STMN1 & rs182455 & $\stackrel{\mathrm{C}}{\mathrm{T}}$ & - & & - & $\begin{array}{l}\text { CC (43) } \\
\text { CT }(60) \\
\text { TT }(26)\end{array}$ \\
\hline
\end{tabular}

All frequencies are within Hardy-Weinberg equilibrium, $P>0.05$. 
Table 2 Amygdala volume, in cubic millimeters, as a function of genotype and parcellation method (mean $\left.\pm \mathrm{s} . \mathrm{d} . \mathrm{mm}^{3}\right)$

\begin{tabular}{|c|c|c|c|c|}
\hline \multirow[b]{2}{*}{ Gene } & \multirow[b]{2}{*}{ Polymorphism } & \multirow[b]{2}{*}{ Genotype } & \multicolumn{2}{|c|}{ Parcellation method } \\
\hline & & & Manual $\left(\mathrm{mm}^{3}\right)$ & Freesurfer $\left(\mathrm{mm}^{3}\right)$ \\
\hline \multirow[t]{6}{*}{ SLC6A4 } & 5-HTTLPR & Short/short & $1231.71 \pm 179.64$ & $1669.54 \pm 201.82$ \\
\hline & & Short/long & $1200.66 \pm 148.31$ & $1657.72 \pm 222.88$ \\
\hline & & Long/long & $1258.04 \pm 148.57$ & $1775.08 \pm 246.39$ \\
\hline & STin2 & $12 / 12$ & $1184.92 \pm 137.84$ & $1661.24 \pm 201.42$ \\
\hline & & $10 / 12$ & $1247.87 \pm 181.61$ & $1718.85 \pm 224.44$ \\
\hline & & $10 / 10$ & $1257.00 \pm 126.61$ & $1753.58 \pm 223.15$ \\
\hline \multirow[t]{2}{*}{ OXTR } & rs53576 & $\mathrm{CC}$ & $1230.18 \pm 166.13$ & $1701.59 \pm 214.84$ \\
\hline & & $\mathrm{CT}+\mathrm{TT}$ & $1202.01 \pm 153.47$ & $1689.25 \pm 228.64$ \\
\hline \multirow[t]{3}{*}{ STMN1 } & rs182455 & $\mathrm{CC}$ & $1180.14 \pm 151.57$ & $1701.41 \pm 230.50$ \\
\hline & & CT & $1214.55 \pm 154.43$ & $1651.81 \pm 196.15$ \\
\hline & & $\mathrm{TT}$ & $1304.43 \pm 172.00$ & $1796.21 \pm 227.10$ \\
\hline
\end{tabular}

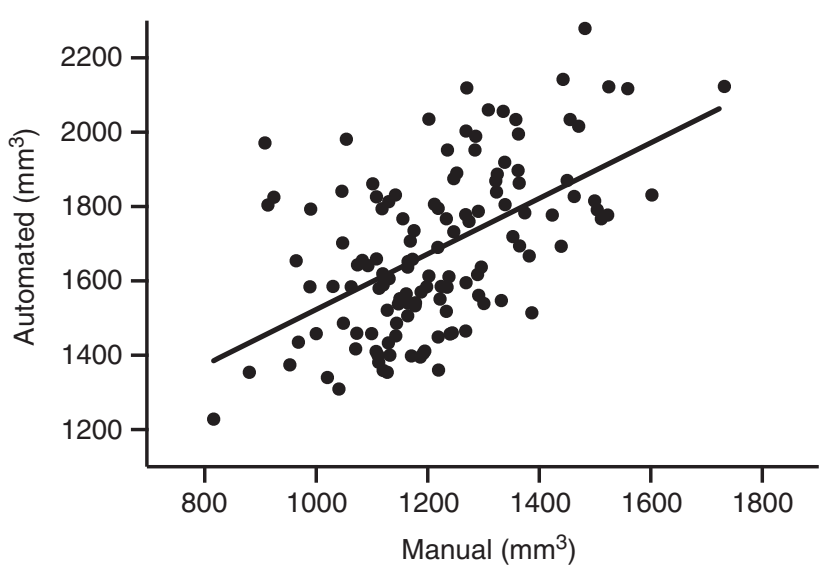

Figure 1 Correlation between amygdala volumes obtain via manual and automated parcellation methods.

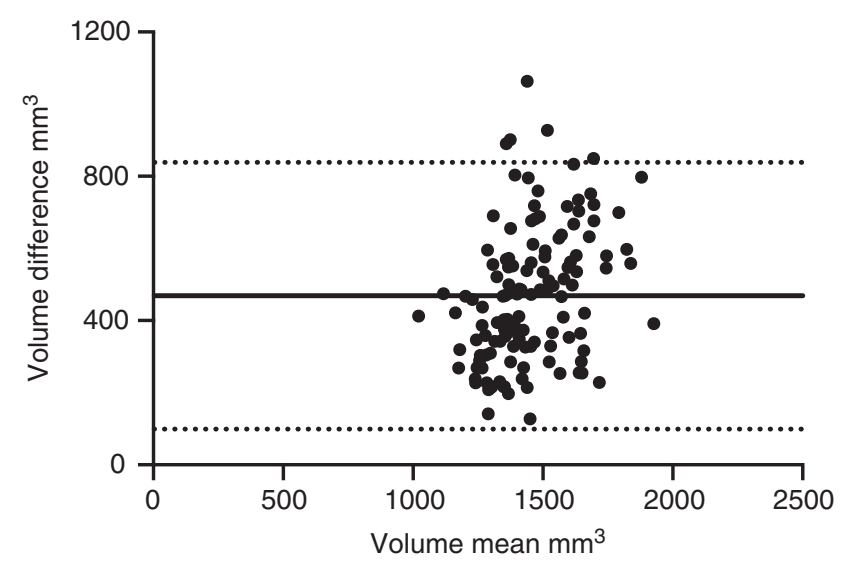

Figure 2 Bland-Altman plot of amygdala volumes obtained by performing the manual and automated parcellation methods. This plot displays the difference between manual and automated volume values against the mean of the two values for each participant, thereby providing a measure of agreement between the two methods. The solid line represents the mean difference between the two methods. Dashed lines represent the limits of agreement, which are defined as 1.96 standard deviations above and below the mean differences.

MRI field strength, ${ }^{66,67}$ sex $^{68,69}$ and total intracranial volume. ${ }^{70}$ We then added in the effect of genes of interest into the regression model. Both covariates and genes of interest were entered using the forced entry method, which makes no assumption as to the order of entry into the regression, and allowed the five genetic variants to be tested together. This method is advantageous when there is no strong theoretical basis for a specific order of entry, and is able to test all genetic variants together. ${ }^{71}$

The regression models at steps 1 and 2 were significant for volumes obtained from both of our parcellation methods (see Table 3). First, we found a significant influence of confounding variables on amygdala volumes. Although only intracranial volume predicted amygdala volumes obtained with manual tracing, amygdala volumes resulting from the automated protocol were significantly affected by intracranial volume and MRI magnet field strength, indicating a difference between the two parcellation methods.

When we examined the impact of genes of interest on amygdala volumes, we found that the stathmin rs182455 and the serotonin transporter STin2 variants were significantly associated with amygdala volumes obtained from manual tracing, whereas this effect was weaker on amygdala volumes resulting from utilizing the automated protocol.

\section{Discussion}

To our knowledge, this is the first study to explore the association between amygdala volume and key novel genetic variants implicated in normative emotional functioning as well as a range of common neuropsychiatric disorders. Furthermore, we compared the sensitivity of manual and automated (that is, Freesurfer) methods of amygdala parcellation in detecting genetic effects on amygdala volume. Our findings indicate that variation in stathmin rs182455 and, to a lesser extent, in serotonin transporter STin2 polymorphism is associated with individual differences in amygdala volumes measured with both manual and automated methods. Notably this association was stronger for the manually traced compared with the automatically segmented amygdala volumes.

The observed association between the number of $\mathrm{C}$ alleles and amygdala volume provides the first evidence of an influence of rs182455 on amygdala volume in healthy humans. Amygdala volumes were reduced in participants with an increasing dose of the stathmin rs182455 C allele, and 


\begin{tabular}{|c|c|c|c|c|c|c|c|c|c|c|c|c|}
\hline \multirow[b]{3}{*}{ Measures } & \multicolumn{12}{|c|}{ Amygdala parcellation method } \\
\hline & \multicolumn{6}{|c|}{ Manual } & \multicolumn{6}{|c|}{ Automated Freesurfer } \\
\hline & $\mathrm{R}$ & $\mathrm{R}^{2}$ & $\Delta \mathrm{R}^{2}$ & F change & $\beta$ & Cohen's $\mathrm{f}^{2}$ & $\mathrm{R}$ & $\mathrm{R}^{2}$ & $\Delta \mathrm{R}^{2}$ & F change & $\beta$ & Cohen's $\mathrm{f}^{2}$ \\
\hline $\begin{array}{l}\text { Step } 1 \\
\text { Covariates }\end{array}$ & 0.470 & 0.221 & 0.221 & $9.439^{\star * *}$ & & & 0.732 & 0.538 & 0.538 & $39.321^{\star \star \star}$ & & \\
\hline $\begin{array}{l}\text { Sex } \\
\text { Magnet } \\
\text { Intracranial volume }\end{array}$ & & & & & $\begin{array}{l}-0.101 \\
0.105 \\
0.405^{\star \star \star}\end{array}$ & $\begin{array}{l}0.008 \\
0.014 \\
0.133\end{array}$ & & & & & $\begin{aligned} &- 0.148 \\
& 0.501^{\star \star \star} \\
& 0.498^{\star \star \star}\end{aligned}$ & $\begin{array}{l}0.030 \\
0.515 \\
0.338\end{array}$ \\
\hline $\begin{array}{l}\text { Step } 2 \\
\text { Covariates }\end{array}$ & 0.591 & 0.349 & 0.129 & $3.760^{\star *}$ & & & 0.764 & 0.585 & 0.047 & $2.861^{*}$ & & \\
\hline $\begin{array}{l}\text { Sex } \\
\text { Magnet } \\
\text { Intracranial volume }\end{array}$ & & & & & $\begin{array}{l}-0.116 \\
0.059 \\
0.398^{\star \star \star}\end{array}$ & $\begin{array}{l}0.011 \\
0.004 \\
0.125\end{array}$ & & & & & $\begin{aligned}-0.169^{\star} \\
0.484^{\star \star \star} \\
0.491^{\star \star \star}\end{aligned}$ & $\begin{array}{l}0.037 \\
0.466 \\
0.314\end{array}$ \\
\hline $\begin{array}{l}\text { Genetic predictors } \\
\text { 5-HTTLPR } \\
\text { STin2 } \\
\text { rs25531 } \\
\text { rs53576 } \\
\text { rs182455 }\end{array}$ & & & & & $\begin{array}{c}0.016 \\
-0.210^{\star} \\
0.089 \\
-0.103 \\
-0.249^{\star \star}\end{array}$ & $\begin{array}{l}0.000 \\
0.009 \\
0.048 \\
0.013 \\
0.071\end{array}$ & & & & & $\begin{array}{r}0.106 \\
-0.106 \\
0.028 \\
0.028 \\
-0.139^{*}\end{array}$ & $\begin{array}{l}0.021 \\
0.002 \\
0.021 \\
0.001 \\
0.038\end{array}$ \\
\hline
\end{tabular}

${ }^{\star} P<0.05,{ }^{\star \star} P<0.01,{ }^{\star * \star} P<0.001$

this result was confirmed by both manual and automated methods of amygdala parcellation. This finding is particularly interesting given the wide distribution of stathmin within the brain, and the amygdala in particular, and its function as a major signaling protein. ${ }^{44,72,73}$ The wide distribution and role of stathmin suggests that there may exist other brain regions wherein morphometric or functional changes are present as a result of genetic variation in the stathmin gene. Specific to the amygdala, stathmin knock-out mice have been previously reported to display deficiencies in threat assessment that mimicked mice with lesions in the basolateral amygdala. ${ }^{45}$ This effect of stathmin upon amygdala structure is echoed by the present findings of an association between the number of $C$ alleles and amygdala volume, and provides the first evidence of an influence of rs182455 on amygdala volume in healthy humans. An effect of rs182455 on amygdala volume may, in turn, contribute to the previously reported genetic effects on cognitive and affective control processes, ${ }^{49}$ and startle response to affective stimuli. ${ }^{47}$ Future research may benefit from the use of amygdala volume as a mediating variable when investigating the relationship between stathmin rs182455 variation and cognitive and affective processing.

In addition to effects of stathmin rs182455, we also observed increased amygdala volume in the presence of the 10-repeat allele of STin2. This association, however, was only significant for manually measured amygdala volumes. This is an intriguing finding given the association of the 10-repeat allele of this marker with a number of psychiatric disorders, ${ }^{37,74-76}$ suggesting that alteration in amygdala volume may provide a useful mediating variable between variation in STin2 and risk for mental illness. Future research is necessary to explore this potential relationship by directly testing the ability of amygdala volume variation to mediate relationships between STin2 variation and risk for or the presence of disease.

Our findings do not confirm previous reports ${ }^{25,69}$ of an association between amygdala volume and allelic variation in the 5-HTTLPR polymorphism. This was despite the current study having a relatively larger sample size and greater power to detect any existing effects. Similarly, we did not detect any effect of variation in the oxytocin receptor polymorphism rs53576 on amygdala volume.

The use of both automated and manual parcellation protocols allowed a direct comparison of the sensitivity of these methods to detect small genetic effects. Results for the automated parcellation method replicated those obtained from the manual parcellation, with weaker effects for rs182455 and no effect of STin2 for manual parcellation. Similarly, there was a significant effect of the nuisance variable of magnet field strength on our model for the automated parcellation but not manual tracing method. These results suggest that the application of automated protocols such as Freesurfer enable the detection of subtle genetic effects on brain structure, albeit with reduced sensitivity compared with manual tracing. This finding is particularly relevant given the increasing use of automated protocols and provides a cautionary note to future studies, in particular those seeking to combine data across multiple sites and scanner environments in order to increase sample size for genetic analyses.

The reported findings are noteworthy given that the amygdala is central to many aspects of affective and social processing and is consistently implicated in a range of common neurodevelopmental and neuropsychiatric disorders. Notably, our findings were partially replicated across both manual and automated amygdala parcellation methods, with manual tracing being more sensitive to the effect of the examined genetic variations on amygdala volumes. The present results provide insight into the potential mechanisms by which variation in these genes may influence healthy cognitive and affective functioning, and ultimately contribute to risk for mental illness. This study was limited, however, in the number of genes that were investigated. There remain many DNA variants that could potentially associate with measures of amygdala function and affective processing that have not been explored. ${ }^{77-83}$ Future work should address this 
limitation, focusing in particular on genes that regulate neural plasticity such as STMN1 and BDNF. ${ }^{83} \mathrm{~A}$ deeper understanding of the genetic influences on amygdala volume variation in normative samples will be key to inform future research investigating the association between amygdala volume and risk of developing psychiatric disorders.

\section{Conflict of interest}

The authors declare no conflict of interest.

Acknowledgements. This work was supported by grants from the Australian Research Council (DP0770337) to MAB and from the Australian National Health and Medical Research Council to MAB and ZH (569532; 1002458; 1006573). Professor Yücel is supported by an NHMRC Fellowship Award (ID: 1021973). Dr Lorenzetti is supported by a Melbourne Neuroscience Institute post-doctoral fellowship.

Disclaimer: The funders had no role in study design, data collection and analysis, decision to publish, or preparation of the manuscript.

1. Dolan RJ. Emotion, cognition, and behavior. Science 2002; 298: 1191-1194.

2. Whittle S, Allen NB, Lubman DI, Yücel M. The neurobiological basis of temperament: towards a better understanding of psychopathology. Neurosci Biobehav Rev 2006; 30 511-525.

3. Adolphs R, Gosselin F, Buchanan TW, Tranel D, Schyns P, Damasio AR. A mechanism for impaired fear recognition after amygdala damage. Nature 2005; 433: 68-72.

4. Killcross S, Robbins TW, Everitt BJ. Different types of fear-conditioned behaviour mediated by separate nuclei within amygdala. Nature 1997; 388: 377-380.

5. McDonald RJ, White NM. A triple dissociation of memory systems: hippocampus, amygdala, and dorsal striatum. Behav Neurosci 1993; 107: 3-22.

6. Adolphs R, Tranel D, Denburg N. Impaired emotional declarative memory following unilateral amygdala damage. Learn Mem 2000; 7: 180-186.

7. Young AW, Aggleton JP, Hellawell DJ, Johnson M, Broks P, Hanley JR. Face processing impairments after amygdalotomy. Brain 1995; 118: 15-24.

8. Broks P, Young AW, Maratos EJ, Coffey PJ, Calder AJ, Isaac CL et al. Face processing impairments after encephalitis: amygdala damage and recognition of fear. Neuropsychologia 1998; 36: 59-70.

9. Lipka J, Miltner WHR, Straube T. Vigilance for threat interacts with amygdala responses to subliminal threat cues in specific phobia. Biol Psychiat 2011; 70: 472-478.

10. Stein MB, Goldin PR, Sareen J, Zorrilla LTE, Brown GG. Increased amygdala activation to angry and contemptuous faces in generalized social phobia. Arch Gen Psychiat 2002; 59 1027-1034

11. Canli T, Sivers H, Thomason ME, Whitfield-Gabrieli S, Gabrieli JDE, Gotlib IH. Brain activation to emotional words in depressed vs healthy subjects. Neuroreport 2004; 15 : 2585-2588.

12. Canli T, Cooney RE, Goldin P, Shah M, Sivers H, Thomason ME et al. Amygdala reactivity to emotional faces predicts improvement in major depression. Neuroreport 2005; 16 : $1267-1270$.

13. Hamilton JP, Siemer M, Gotlib IH. Amygdala volume in major depressive disorder: a metaanalysis of magnetic resonance imaging studies. Mol Psychiatry 2008; 13: 993-1000.

14. Szeszko PR, Robinson D, Alvir JM, Bilder RM, Lencz T, Ashtari M et al. Orbital frontal and amygdala volume reductions in obsessive-compulsive disorder. Arch Gen Psychiat 1999 56: 913-919.

15. Dalton KM, Nacewicz BM, Alexander AL, Davidson RJ. Gaze-fixation, brain activation, and amygdala volume in unaffected siblings of individuals with autism. Biol Psychiat 2007; 61: 512-520.

16. Hulshoff Pol HE, Schnack HG, Posthuma D, Mandl RCW, Baaré WFC, van Oel C et al. Genetic contributions to human brain morphology and intelligence. J Neurosci 2006; 26 : 10235-10242

17. Kremen WS, Prom-Wormley E, Panizzon MS, Eyler LT, Fischl B, Neale MC et al. Genetic and environmental influences on the size of specific brain regions in midlife: the VETSA MRI study. Neurolmage 2010; 49: 1213-1223.

18. Wendland JR, Martin BJ, Kruse MR, Lesch K-PP, Murphy DL. Simultaneous genotyping of four functional loci of human SLC6A4, with a reappraisal of 5-HTTLPR and rs25531. Mol Psychiatry 2006; 11: 224-226.

19. Kraft JB, Slager SL, McGrath PJ, Hamilton SP. Sequence analysis of the serotonin transporter and associations with antidepressant response. Biol Psychiat 2005; 58 : 374-381.

20. Heils A, Teufel A, Petri S, Stöber G, Riederer P, Bengel D et al. Allelic variation of human serotonin transporter gene expression. J Neurochem 1996; 66: 2621-2624.
21. Rao H, Gillihan SJ, Wang J, Korczykowski M, Sankoorikal GMV, Kaercher KA et al. Genetic variation in serotonin transporter alters resting brain function in healthy individuals. Biol Psychiat 2007; 62: 600-606.

22. Hariri AR, Mattay VS, Tessitore A, Kolachana B, Fera F, Goldman D et al. Serotonin transporter genetic variation and the response of the human amygdala. Science 2002; 297 400-403.

23. Serretti $A$, Kato M, de Ronchi D, Kinoshita T. Meta-analysis of serotonin transporter gene promoter polymorphism (5-HTTLPR) association with selective serotonin reuptake inhibitor efficacy in depressed patients. Mol Psychiatry 2007; 12: 247-257.

24. Munafò MR, Brown SM, Hariri AR. Serotonin transporter (5-HTTLPR) genotype and amygdala activation: a meta-analysis. Biol Psychiat 2008; 63: 852-857.

25. Scherk H, Gruber O, Menzel P, Schneider-Axmann T, Kemmer C, Usher J et al. 5-HTTLPR genotype influences amygdala volume. Eur Arch Psychiatry Clin Neurosci 2009; 259: 212-217.

26. Hu X-Z, Lipsky RH, Zhu G, Akhtar LA, Taubman J, Greenberg BD et al. Serotonin transporter promoter gain-of-function genotypes are linked to obsessive-compulsive disorder. Am J Hum Genet 2006; 78: 815-826.

27. Hu X-Z, Oroszi G, Chun J, Smith TL, Goldman D, Schuckit MA. An expanded evaluation of the relationship of four alleles to the level of response to alcohol and the alcoholism risk. Alcohol Clin Exp Res 2005; 29: 8-16.

28. Martin J, Cleak J, Willis-Owen SAG, Flint J, Shifman S. Mapping regulatory variants for the serotonin transporter gene based on allelic expression imbalance. Mol Psychiatry2007; 12 : $421-422$.

29. Parsey RV, Hastings RS, Oquendo MA, Hu X, Goldman D, Huang Y-Y et al. Effect of a triallelic functional polymorphism of the serotonin-transporter-linked promoter region on expression of serotonin transporter in the human brain. Am J Psychiatry 2006; 163: 48-51.

30. Jasinska AJ, Chua HF, Ho SS, Polk TA, Rozek LS, Strecher VJ. Amygdala response to smoking-cessation messages mediates the effects of serotonin transporter gene variation on quitting. Neurolmage 2012; 60: 766-773.

31. Gelernter J, Cubells JF, Kidd JR, Pakstis AJ, Kidd KK. Population studies of polymorphisms of the serotonin transporter protein gene. Am J Med Genet 1999; 88 61-66.

32. Kohen R, Cain KC, Mitchell PH, Becker K, Buzaitis A, Millard SP et al. Association of serotonin transporter gene polymorphisms with poststroke depression. Arch Gen Psychiat 2008; 65: 1296-1302.

33. MacKenzie A, Quinn J. A serotonin transporter gene intron 2 polymorphic region, correlated with affective disorders, has allele-dependent differential enhancer-like properties in the mouse embryo. Proc Natl Acad Sci USA 1999; 96: 15251-15255.

34. Fiskerstrand CE, Lovejoy EA, Quinn JP. An intronic polymorphic domain often associated with susceptibility to affective disorders has allele dependent differential enhancer activity in embryonic stem cells. FEBS Lett 1999; 458: 171-174.

35. Lovejoy EA, Scott AC, Fiskerstrand CE, Bubb VJ, Quinn JP. The serotonin transporter intronic VNTR enhancer correlated with a predisposition to affective disorders has distinct regulatory elements within the domain based on the primary DNA sequence of the repeat unit. Eur J Neurosci 2003; 17: 417-420.

36. Bah J, Lindström M, Westberg L, Mannerås L, Ryding $\mathrm{E}$, Henningsson $\mathrm{S}$ et al. Serotonin transporter gene polymorphisms: effect on serotonin transporter availability in the brain of suicide attempters. Psychiatry Res 2008; 162: 221-229.

37. Ohara K, Suzuki Y, Ochiai M, Tsukamoto T, Tani K, Ohara K. A variable-number-tandemrepeat of the serotonin transporter gene and anxiety disorders. Prog Neuropsychopharmacol Biol Psychiatry 1999; 23: 55-65.

38. Collier DA, Arranz MJ, Sham P, Battersby S, Vallada H, Gill P et al. The serotonin transporter is a potential susceptibility factor for bipolar affective disorder. Neuroreport 1996; 7: 1675-1679.

39. Hranilovic D, Stefulj J, Schwab S, Borrmann-Hassenbach M, Albus M, Jernej B et al Serotonin transporter promoter and intron 2 polymorphisms: relationship between allelic variants and gene expression. Biol Psychiatry 2004; 55: 1090-1094.

40. Ali FR, Vasiliou SA, Haddley K, Paredes UM, Roberts JC, Miyajima F et al. Combinatorial interaction between two human serotonin transporter gene variable number tandem repeats and their regulation by CTCF. J Neurochem 2010; 112: 296-306.

41. Meyer-Lindenberg A, Domes G, Kirsch P, Heinrichs M. Oxytocin and vasopressin in the human brain: social neuropeptides for translational medicine. Nat Rev Neurosci 2011; 12 524-538.

42. Veinante $P$, Freund-Mercier MJ. Distribution of oxytocin- and vasopressin-binding sites in the rat extended amygdala: a histoautoradiographic study. J Comp Neurol 1997; 383: 305-325.

43. Tost $\mathrm{H}$, Kolachana $\mathrm{B}$, Hakimi S, Lemaitre $\mathrm{H}$, Verchinski BA, Mattay VS et al. A common allele in the oxytocin receptor gene (OXTR) impacts prosocial temperament and human hypothalamic-limbic structure and function. Proc Natl Acad Sci USA 2010; 107 13936-13941.

44. Peschanski M, Hirsch E, Dusart I, Doye V, Marty S, Manceau V et al. Stathmin: cellular localization of a major phosphoprotein in the adult rat and human CNS. J Comp Neuro 1993; 337: 655-668.

45. Martel G, Nishi A, Shumyatsky GP. Stathmin reveals dissociable roles of the basolateral amygdala in parental and social behaviors. Proc Natl Acad Sci USA 2008, 105: $14620-14625$ 
46. Shumyatsky GP, Malleret G, Shin R-M, Takizawa S, Tully K, Tsvetkov E et al Stathmin, a gene enriched in the amygdala, controls both learned and innate fear. Cell 2005; 123: 697-709.

47. Brocke B, Lesch K-PP, Armbruster D, Moser DA, Müller A, Strobel A et al. Stathmin, a gene regulating neural plasticity, affects fear and anxiety processing in humans. Am J Med Genet B Neuropsychiatr Genet 2010; 153B: 243-251.

48. Morey RA, Petty CM, Xu Y, Hayes JP, Wagner HR, Lewis DV et al. A comparison of automated segmentation and manual tracing for quantifying hippocampal and amygdala volumes. Neurolmage 2009; 45: 855-866.

49. Ehlis A-C, Bauernschmitt K, Dresler T, Hahn T, Herrmann MJ, Röser C et al. Influence of a genetic variant of the neuronal growth associated protein Stathmin 1 on cognitive and affective control processes: an event-related potential study. Am J Med Genet B Neuropsychiatr Genet 2011; 156B: 291-302.

50. Jenkinson M, Beckmann CF, Behrens TEJ, Woolrich MW, Smith SM. FSL. Neurolmage 2012; 62: 782-790.

51. Smith SM. Fast robust automated brain extraction. Human Brain Mapping 2002; 17 143-155.

52. Jenkinson M, Bannister P, Brady M, Smith S. Improved optimization for the robust and accurate linear registration and motion correction of brain images. Neurolmage 2002; 17 : 825-841.

53. Velakoulis D, Wood SJ, Wong MTH, McGorry PD, Yung A, Phillips L et al. Hippocampal and amygdala volumes according to psychosis stage and diagnosis: a magnetic resonance imaging study of chronic schizophrenia, first-episode psychosis, and ultra-high-risk individuals. Arch Gen Psychiat 2006; 63: 139-149.

54. Watson C, Andermann F, Gloor P, Jones-Gotman M, Peters T, Evans A et al. Anatomic basis of amygdaloid and hippocampal volume measurement by magnetic resonance imaging. Neurology 1992; 42: 1743-1750.

55. Lorenzetti V, Allen NB, Whittle S, Yücel M. Amygdala volumes in a sample of current depressed and remitted depressed patients and healthy controls. J Affect Disord 2010; 120: $112-119$.

56. Rozen S, Skaletsky H. Primer3 on the WWW for general users and for biologist programmers. Methods Mol Biol 2000; 132: 365-386.

57. Sarosi A, Gonda X, Balogh G, Domotor E, Szekely A, Hejias K et al. Association of the STin2 polymorphism of the serotonin transporter gene with a neurocognitive endophenotype in major depressive disorder. Prog Neuropsychopharmacol Biol Psychiatry 2008; 32: 1667-1672.

58. Rodrigues SM, Saslow LR, Garcia N, John OP, Keltner D. Oxytocin receptor genetic variation relates to empathy and stress reactivity in humans. Proc Natl Acad Sci USA 2009; 106: 21437-21441.

59. Bakermans-Kranenburg MJ, van ljzendoorn MH. Oxytocin receptor (OXTR) and serotonin transporter (5-HTT) genes associated with observed parenting. Soc Cogn Affect Neurosci 2008; 3: 128-134.

60. Herzog AG, Kemper TL. Amygdaloid changes in aging and dementia. Arch Neurol 1980; 37: 625-629.

61. Bogerts B, Meertz E, Schönfeldt-Bausch R. Basal ganglia and limbic system pathology in schizophrenia. A morphometric study of brain volume and shrinkage. Arch Gen Psychiat 1985; 42: 784-791.

62. Heckers S, Heinsen $\mathrm{H}$, Heinsen $Y C$, Beckmann $\mathrm{H}$. Limbic structures and lateral ventricle in schizophrenia: a quantitative postmortem study. Arch Gen Psychiat 1990; 47: 1016-1022.

63. Scott SA, DeKosky ST, Scheff SW. Volumetric atrophy of the amygdala in Alzheimer's disease: quantitative serial reconstruction. Neurology 1991; 41: 351-356.

64. Bland JM, Altman DG. Statistical methods for assessing agreement between two methods of clinical measurement. Lancet 1986; 1: 307-310.

65. Bland JM, Altman DG. Measuring agreement in method comparison studies. Stat Methods Med Res 1999; 8: 135-160.

66. Nugent AC, Luckenbaugh DA, Wood SE, Bogers W, Zarate CA, Drevets WC. Automated subcortical segmentation using FIRST: Test-retest reliability, interscanner reliability, and comparison to manual segmentation. Hum Brain Map 2013 (in press).
67. Pedraza O, Bowers D, Gilmore R. Asymmetry of the hippocampus and amygdala in MRI volumetric measurements of normal adults. J Int Neuropsychol Soc 2004; 10: 664-678.

68. Chance SA, Esiri MM, Crow TJ. Amygdala volume in schizophrenia: post-mortem study and review of magnetic resonance imaging findings. Br J Psychiatry 2002; 180: 331-338.

69. Pezawas L, Meyer-Lindenberg A, Drabant EM, Verchinski BA, Munoz KE, Kolachana BS et al. 5-HTTLPR polymorphism impacts human cingulate-amygdala interactions: a genetic susceptibility mechanism for depression. Nat Neurosci 2005; 8: 828-834.

70. Brierley B, Shaw P, David AS. The human amygdala: a systematic review and metaanalysis of volumetric magnetic resonance imaging. Brain Res Brain Res Rev 2002; 39: 84-105.

71. Field A. Discovering Statistics Using SPSS. 3rd edn SAGE Publications Limited: London, UK, 2009.

72. Jourdain L, Curmi P, Sobel A, Pantaloni D, Carlier M-F. Stathmin: a tubulin-sequestering protein which forms a ternary T2S complex with two tubulin molecules. Biochemistry 1997; 36: 10817-10821.

73. Rubin $\mathrm{Cl}$, Atweh GF. The role of stathmin in the regulation of the cell cycle. J Cell Biochem 2004; 93: 242-250.

74. Baca-Garcia E, Vaquero-Lorenzo C, Diaz-Hernandez M, Rodriguez-Salgado B, Dolengevich-Segal H, Arrojo-Romero M et al. Association between obsessive-compulsive disorder and a variable number of tandem repeats polymorphism in intron 2 of the serotonin transporter gene. Prog Neuropsychopharmacol Biol Psychiatry 2007; 31: 416-420.

75. Fan JB, Sklar P. Meta-analysis reveals association between serotonin transporter gene STin2 VNTR polymorphism and schizophrenia. Mol Psychiatry 2005; 10: 928-38-891.

76. Collier DA, Stöber G, Li T, Heils A, Catalano M, Di Bella D et al. A novel functional polymorphism within the promoter of the serotonin transporter gene: possible role in susceptibility to affective disorders. Mol Psychiatry 1996; 1: 453-460.

77. Andrus BM, Blizinsky K, Vedell PT, Dennis K, Shukla PK, Schaffer DJ et al. Gene expression patterns in the hippocampus and amygdala of endogenous depression and chronic stress models. Mol Psychiatry 2012; 17: 49-61.

78. Cerasa A, Quattrone A, Gioia MC, Magariello A, Muglia M, Assogna F et al. MAO A VNTR polymorphism and amygdala volume in healthy subjects. Psychiatry Res 2011; 191: 87-91.

79. Domschke K, Baune BT, Havlik L, Stuhrmann A, Suslow T, Kugel H et al. Catechol-Omethyltransferase gene variation: Impact on amygdala response to aversive stimuli. Neurolmage 2012; 60: 2222-2229.

80. Fakra E, Hyde LW, Gorka A, Fisher PM, Munoz KE, Kimak M et al. Effects of HTR1A C(-1019)G on amygdala reactivity and trait anxiety. Arch Gen Psychiat 2009; 66: 33-40.

81. Booij L, Turecki G, Leyton M, Gravel P, Lopez De Lara C, Diksic M et al. Tryptophan hydroxylase2 gene polymorphisms predict brain serotonin synthesis in the orbitofrontal cortex in humans. Mol Psychiatry 2012; 17: 809-817.

82. Lohoff FW, Hodge R, Narasimhan S, Nall A, Ferraro TN, Mickey BJ et al. Functional genetic variants in the vesicular monoamine transporter 1 modulate emotion processing. Mol Psychiatry 2013 (in press).

83. Outhred T, Das P, Dobson-Stone C, Griffiths K, Felmingham KL, Bryant RA et al. The functional epistasis of 5-HTTLPR and BDNF Val66Met on emotion processing: a preliminary study. Brain Behav 2012; 2: 778-788.

(c) (1) (2) () Translational Psychiatry is an open-access journal published by Nature Publishing Group. This work is licensed under a Creative Commons Attribution-NonCommercialShareAlike 3.0 Unported License. To view a copy of this license, visit http://creativecommons.org/licenses/by-nc-sa/3.0/ 